were advancing the view that implanted vascular tissues resumed active, vital functions, even when the tisosues employed had been removed for considerable periods from the body, or when their source was of a species different from the host. Our results from implanting vascular segments of cat and rabbit into dog, namely, effecting a restoration of good mechanical function, notwithstanding profound degenerative changes, had led me to suspect strongly that mechanical function in itself was not evidence of tissue survival; and I had expressed the view that, to restore and maintain mechanical function, such an implanted segment need only temporarily restore mechanical continuity and serve as a scaffolding or bridge for the laying down of an ingrowth of tissue derived from the host. For this reason, the implanted tissue was subjected to treatment that would, beyond question, assure its complete devitalization. Others have abundantly confirmed the findings, the most recent work being that of Nageotte and Sencert. ${ }^{2}$

An interesting feature of the experiment reported is that it is the first of the kind, as well as the longest in respect to end-results.

- It is planned to report the results in detail elsewhere in collaboration with Prof. Oskar Klotz, to whom my thanks are due for the necroscopic examination, for preparing and preserving the gross specimen, and for conducting the microscopic study of the tissues.

\section{TREATMENT OF GUNSHOT WOUNDS OF THE ABDOMEN *}

\author{
JOHN H. GIBBON, M.D. \\ Colonel, M. C., U. S. Army
}

PHILADELPHIA

In the treatment of gunshot wounds generally, the last five years have witnessed great change and great improvement. In the treatment of gunshot wounds of the chest and of joints the advance has been most striking and will greatly change the civil practice in these fields; but in abdominal surgery it cannot be said that any wonderful change or improvement has been made. Because of the great prevalence of shell wounds over those made by high velocity bullets, operation in these cases has been much more regularly resorted to than, for instance, at the end of the Boer War. During that war it was undoubtedly true that patients did recover after penetrating and perforating wounds of the abdomen; but I cannot say that I saw in nineteen months spent in advanced and base hospitals a single instance of this kind.

In a communication of this length it is impossible to go deeply into the literature of the subject or to give extensive tables of statistics, even if this were desirable, and I shall confine myself to personal experience and observation.

\section{NEEDLESS ABDOMINAL EXPLORATION}

One of the most important things in the treatment of gunshot wounds of the abdomen is the ability to estimate fairly accurately whether the missile has really penetrate the abdominal cavity, and if so what struc-

2. Nageotte, J., and Sencert, L.: Compt. rend. Soc. de biol. 82: 45, 1919.

- Read before the Section on Obstetrics, Gynecology and Abdominal Surgery at the Seventieth Annual Session of the American Medical Association, Atlantic City, June, 1919. tures have probably been damaged. This may not at first thought appear to be of the prime importance that it is, for one may say it is safer to open the abdomen in any case and determine whether penetration has occurred and what viscera, if any, have been injured. But, taking a large number of cases, this is not true; for one would find himself doing an exploratory laparotomy many times when there was no penetration; when the injured viscus, such as the liver, were better undisturbed; when the injury was above and not below the diaphragm, and in many cases in which the patient had multiple wounds and the prolonged negative exploration only added to the risk of life.

If a man has, for instance, a compound fracture of the leg or thigh, and perhaps a number of wounds of less severity, one should be very sure that a wound which would seem to have involved the abdomen really entered it before subjecting the patient to a deliberate abdominal section and a prolonged search for injury of the viscera; the other wounds alone render this case a serious one, and their treatment must require considerable time and involve a prolonged anesthesia. I do not mean, of course, to say that the abdominal wounds are not the most serious, or that they do not demand first consideration; but I would suggest that here, as in civil practice, one has no right to subject a patient to a needless abdominal exploration, especially when care and the exercise of judgment may show that such an operation is unnecessary. Numerous instances illustrating these points must come to the minds of many, and a common observation has been that many wounds which would certainly seem to have involved the abdomen were only wounds of its wall, and that others which were snall and seemed trivial at first sight did involve the abdominal viscera.

\section{VARIOUS TYPES OF WOUNDS}

A common type of wound of the wall which produced shock and abdominal rigidity was that caused by a shell fragment and characterized by a large ragged wound of entrance, probably by a larger one of exit, by extensive ecchymosis, by marked abdominal rigidity, and by costal breathing. In such cases the wound should be excised or débrided and the abdomen should not be opened deliberately at some point of election until penetration has been definitely determined. It is needless to say that probing should never be done. The probe, in fact, should be eliminated from the paraphernalia of the military surgeon. I have seen a number of small and apparently trivial wounds, of the loin and lumbar region particularly, in which either a careful examination or time would show that the missile had penetrated the abdomen. I recall seeing a young officer, being treated for gas poisoning of slight degree in a field hospital, who made very light of a small wound in the left loin; but examination made one suspicious of abdominal penetration, and a few hours later, when he had been transferred to an evacuation hospital and operated on, the suspicion became a certainty.

It can truly be said, then, that to lay down definite rules for action in these cases is difficult, and that experience and judgment, and above all a careful examination of each case, are of prime importance.

Many more lives are lost in this field by "not wasting time in trying to make a diagnosis" and operating at once than by wasting the time in study of the case. It is not so much a question of diagnosis as of determin- 
ing whether or not the abdomen should be opened. In this connection there comes to mind that interesting group of combined chest and abdominal woundsperforations of the diaphragm-in which the surgeon probably has the greatest difficulty in determining his action. It is surprising in how many cases of gunshot wound of the lower chest or those in which a missile lies in or on the diaphragm, the patient will present symptoms which would certainly suggest an abdominal penetration: particularly abdominal rigidity, sometimes later abdominal distention, and frequently hiccup. I can recall six such cases in one evacuation hospital last summer, in any one of which operation might have seemed justified, but in which all six patients recovered without operation.

Still another type of these combined chest and abdominal wounds was that in which the missile penetrates the abdominal wall, perforates the liver and diaphragm, and lodges in the thorax. If the injury is confined to the structures mentioned, and the missile, as disclosed by roentgenoscopy, is not large, no immediate operation should be performed; but the question always came up as to the possibility of injury of the colon or stomach. The probable course of the missile, as indicated by its point of entrance and its location, was of the greatest help in many of these cases. My own rule was not to operate unless there was present a pretty definite indication of injury of a hollow viscus. The wound of the liver and diaphragm alone, except when made by a large foreign body or accompanied by a sucking wound of the chest, was not considered as calling for an immediate operation. I have often regretted operating and suggesting operation in these cases, but I cannot recall a single case in which I regret not having operated or recommending such a course. The situation here can be summarized by saying that if one is fairly certain that the hollow viscera have escaped injury, no operation should be done.

What about hemorrhage? In cases of hemorrhage from the liver caused by gunshot wounds, a few patients are saved by operation, many are not benefited, and not a few are made worse. I believe that nature is more likely to stop bleeding from a gunshot wound passing through the liver than is the surgeon. In some of these cases the missile has injured the kidney as well as the liver and diaphragm, and here the hemorrhage can and should be controlled, or the kidney removed.

\section{TECHNIC}

In regard to the technic of abdominal operations I think there is little to be said, for the war has, I believe, brought about no important changes. Perhaps an exception to this statement can be made in regard to drainage. The rule of closing the abdomen without drainage became established by our allies early in the war, and I believe is a good rule. The war has certainly shown that drainage of any wound is a frequent cause of its infection, and the discontinuance of the abdominal drain represented the application of this general rule to abdominal cases. There are, however, many cases, especially of wounds involving the large intestine and bladder, in which it would have been foolish not to drain.

An observation which I made, after a few months' service in a British base hospital in France, was that although many men with gunshot wounds of the abdomen were admitted in good condition a week or ten days after operation, yet a number of them later devel- oped an infection of the wound and it had to be laid wide open. This occurred so often that later in my own work at a British clearing station I followed the plan in every instance in which evacuation was necessary within ten days-and this was true in most cases - of closing all the layers of the abdominal wall excepting the skin and placing sutures through the skin which could be tied later, if no infection occurred. I learned from Brewer that he had reached the same conclusion and followed the same practice. These late infections, I believe, occurred from the skin, and they were also frequently seen after complete closure of the chest and knee-joint wounds. Of course, in the latter two situations it is much mote difficult to close off the cavity thoroughly, without closure of the skin, than it is in the case of abdominal wounds. I am sure from my personal experience that the late closure of the skin prevented an infection in many cases. It is true that the late infection of the abdominal wound practically never gave rise to an infection of the peritoneal cavity, whereas such an infection in a chest wound or in a wound of the knee-joint almost invariably resulted in an infection of the underlying cavity. My impression is that when an abdominal drain is employed, it should be a loose gauze drain covered with rubber dam or rubber tissue. The hard, rigid, rubber tubing, or uncovered gauze drains are much more apt to give rise to dense adhesions, which may later produce obstruction or, by pressure, necrosis.

\section{MORTALITY}

The mortality in gunshot wounds of the abdomen was extremely high, and a large proportion of this mortality occurred on the field or before the patient reached an advanced operating center, anci hemorrhage and shock were its two most potent causes. But the mortality in those cases in which the wounded did reach the operating center was also high, largely for the same reasons, but often because the patient suffered from multiple wounds, the repair of which meant prolonged anesthesia and increased shock. From what I have seen of the late results, I should say that the mortality was not so high as might be expected from late complications in the case of those who recovered from the primary effects of their wound and the operation.

A common observation was that the prisoners with abdominal wounds seemed to stand operation better than our own soldiers, and that the mortality among them was not so high. This, I believe, was due to the fact that they were not operated on with the promptness, I may say haste, that was exercised in the case of our own men. If this observation is correct, the inference is obvious: that it is a mistake to operate on gunshot wounds of the abdomen until the patient has recovered from the shock sufficiently to stand operation, unless the shock is due to hemorrhage. To determine whether the shock is due to hemorrhage was, in many instances, very difficult; but when it was not due to hemorrhage, much better operative results were obtained by waiting. All of the patients, of course, have lost a certain amount of blood; and the important question to decide is whether the bleeding is continuing. One cannot resort to exploratory laparotomy with the same impunity that he would in civil life, because in most instances the patient is suffering from more than one wound, and the operation, which is indicated, must of necessity occupy a much longer period of time and 
necessitate the employment of a much larger quantity of the anesthetic agent, two factors which largely increase the immediate operative mortality.

\section{ABSTRACT OF DISCUSSION}

Dr. Edward W. Meredith, Pittsburgh: In the case of patients arriving with abdominal wounds which seemed to have penetrated the peritoneum we were able, on account of the absence of rigidity, vomiting and because of the generally good condition of the patient, to say that this patient did not have a penetrating wound of the abdominal cavity. This gave us an opportunity to operate on the wounded men most in need of immediate attention, and to leave the treatment of other patients for a more convenient time. The average time of arrival of patients after injury was twenty hours. In cases in which a hollow viscus was penetrated the question was that of diagnosing peritonitis. We did have abdominal rigidity, some distention and some rise in pulse rate, in addition to the rise that might come from hemorrhage, to aid us in diagnosis. The surgical proposition, therefore, was that of treatment of peritonitis. In none of these cases, except a case of ruptured spleen, was there any question of serious hemorrhage. Four patients with wounds of the chest and abdomen were operated on; two patients had a ruptured spleen; one patient had a ruptured kidney; the fourth patient showed no visceral lesions. The two patients with ruptured spleen died from preoperative and postoperative hemorrhage. All patients were placed in the shock ward, both for observation and resuscitation. After a long ambulance ride, with more or less exposure to cold, with pain and loss of fluids they arrived in a much shocked condition and with depressed vitality. After two or three hours rest in a warm bed there was usually considerable improvement, if anything could be done. Perhaps we used drainage more than Dr. Gibbon did. We found it necessary to drain in 30 per cent. of the cases. The abdominal wall was sutured, with the exception of the skin-following the general rule laid down in the A. E. F. not to suture the skin. We did, however, suture the remaining layers of the abdominal wall. The chest cases in which it was possible that there might be combined abdominal injury were treated conservatively as were all chest cases in our hospital. In wounds of the lower chest wall, in which abdominal distention might be expected, we followed the same rule of depending on rigidity of the abdomen to determine whether an operation should be done. If we could satisfy ourselves that no abdominal hollow viscus had been injured we followed the conservative plan as in the straight chest cases. The difference between military and civilian surgery in cases of wounds of the abdomen is not great. We have nothing special to offer in improved technic in the operation itself. We were handicapped, of course, by the lateness of the patient's arrival. In civilian life this interval would certainiy be less than twenty hours. We were handicapped also at times by the rush of patients, and by questioning whether it was advisable to operate in some of the more serious abdominal cases or to operate first on patients who were more lightly injured that they might be restored more quickly. We did not refuse any patient an operation because of the seriousness of his condition. The larger percentage of patients arriving in our hospital reached there in fair condition. Outside of the difference in time of seeing the patient after injury there is little difference between military and civilian surgery.

Is Your Community Fit?-Are your schools provided with medical supervision to control the spread of communicable diseases among the children and to limit the number of sources of contagious diseases which often spread rapidly when carried to susceptible persons? Do your children have the advantage of regular physical examination by a physician? Is there a clinic for the treatment of all the physical defects discovered as a result of this examination? The after-war development of your community will depend largely on the physical fitness of your present school population.Pub. Health Rep., April 25, 1919.

\section{SURVEY OF THE EPIDEMIC OF INFLU- ENZA IN THE AMERICAN EXPE- DITIONARY FORCES *}

\author{
WARFIELD T. LONGCOPE, M.D. \\ NEW YORK
}

The origin of the epidemic of influenza and its invasion of Europe is still obscure; but it is certain that influenza existed in epidemic form in Spain, France and possibly England, early in 1918, and it may even have been present in endemic form during the previous year. By May, 1918, there was in Spain a widespread epidemic which received much publicity. In April or May there were local outbreaks of the disease, according to the report of the British commission, in the first and second British armies, and by the late spring influenza was present in epidemic form, not only in Spain and in France, affecting both the British and the American armies, but also in Italy, Belgium, Austria and Germany.

Until the complete official reports of the incidence of influenza in the American Expeditionary Forces are made available and the statistics of the epidemic published, it is impossible to give figures or similar accurate data which bear on the epidemiology of this disease among our own troops in France. A paper by Dr. Ward J. MacNeal, ${ }^{1}$ assistant to the director of laboratories and infectious disease, American Expeditionary Forces, which recently appeared, is an official report on the epidemic, and contains considerable data of interest. Dr. MacNeal kindly allowed me to see the manuscript and to quote from it. Much of what I have to say, nevertheless, must be based on personal observations that are of necessity fragmentary and limited.

As one reviews the history of the epidemic in France, it may be divided into three fairly definite outbreaks with an intermediate and interesting phase bridging the gap between the second and third outbreaks.

The first outbreak appeared in April and May, 1918. It was comparatively mild and spoken of as "three day fever."

The second outbreak came in September and October, 1918, and formed a part of the terrible pandemic.

The third definite outbreak, according to recent reports, was much less serious, and occurred in January and February, 1919.

The fourth or intermediate phase was represented by scattered cases of influenza and great numbers of respiratory infections, either unaccompanied by pneumonia or associated with a pneumonia of the true lobar type. This phase followed the second great outbreak, and continued during the autumn and winter of 19181919.

\section{THE FIRST OUTBREAK}

In the first outbreak the earliest recorded epidemic among the American Expeditionary Forces appeared, according to MacNeal, about $\Lambda$ pril 1, 1918, at Rest Camp No. 4 in Base Section 2, near Bordeaux. It reached its height, April 22, and ceased, May 5. In May, 1918, a second outbreak of influenza was reported from the Quartier de Beaumont, Tours, which lasted from May 1 to May 24, and affected 117 persons.

* Read before the Section on Practice of Medicine at the Seventieth Annual Session of the American Medical Association, Atlantic City, N. J., June, 1919

1. MacNeal, W. J.: The Influenza Epidemic of 1918 in the American Expeditionary Forces in France and England, Arch. Int. Med. 23: 657
(June) 1919. 